Published online on the journal's webpage: http://jurnal.iaii.or.id

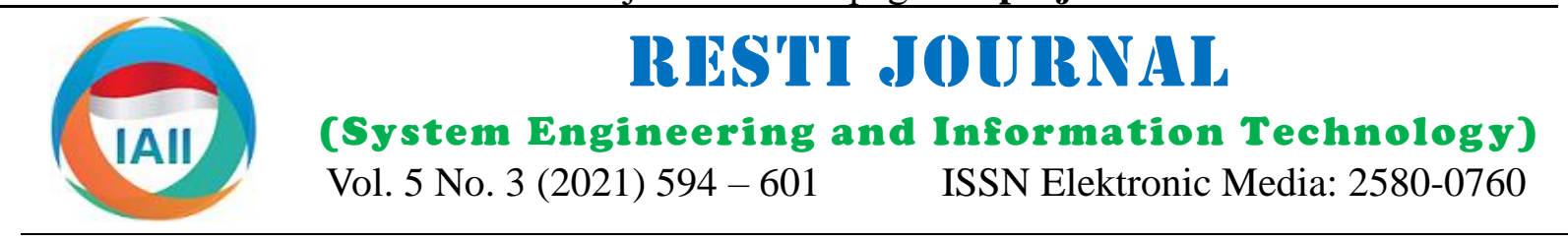

\title{
Classifying Quranic Verse Topics using Word Centrality Measure
}

\author{
Ferdian Yulianto $^{1}$, Kemas M. Lhaksmana ${ }^{2}$, Danang Triantoro Murdiansyah ${ }^{3}$ \\ ${ }^{1,2,3}$ Informatics, School of Computing, Telkom University \\ ${ }^{1}$ ferdiany@student.telkomunivesity.ac.id, ${ }^{2}$ kemasmuslim@telkomuniversity.ac.id, ${ }^{3}$ danangtri@ telkomuniversity.ac.id
}

\begin{abstract}
Muslims believe that, as the speech of Allah, The Quran is a miracle that has specialties in itself. Some of the specialties that have studied are the regularities in the number of letters, words, vocabularies, etc. In the past, the early Islamic scholars identify these regularities manually, i.e. by counting the occurrence of each vocabulary by hand. This research tackles this problem by utilizing centrality in quranic verse topic classification. The goal of this research is to analyze the effect of The Quran word centrality measure on the topic classification of The Quran verses. To achieve this objective, the method of this research is constructing the Quran word graph, then the score of centralities included as one of the features in the verse topic classification. The effect of centrality is observed along with support vector machine (SVM) and naïve Bayes classifiers by performing two scenarios (with stopword and without stopword removal). The result shows that according to the centrality measure the word "alll" (Allah) is the most central in The Quran. The performance evaluation of the classification models shows that the use of centrality improves the hamming loss score from 0.43 to 0.21 on naïve Bayes classifier with stopword removal. Finally, both of classification method has a better performance in word graph that use stopword removal.
\end{abstract}

Keywords: The Holy Quran, centrality, topic classification, SVM, naïve Bayes, multilabel classification.

\section{Introduction}

The Quran is the holy book of Muslims that is used as a guide for life. It consists of 30 parts (juz), 114 chapters, and 6236 verses. As the speech of The God which was revealed to the Prophet Muhammad (praised be upon him) through the archangel Gabriel, muslims believe that The Quran is a miracle which has many specialties. Its miracle and specialties have been studied by Islamic scholars from many aspects, especially its content as the primary source of Islam. Other Islamic scholars also studied other specialties of The Quran from linguistic aspects, such as the regularities on the number of letters, words, vocabularies, etc.

Muslims believe that The Quran has regularities in terms of the number of vocabularies and relationships between words in verses which make these verses have a different topic. In graph theory, centrality measurement identifies how important nodes are close to each other. Centrality measurement can be used to distinguish important nodes in the graph [1].
In recent years, there are various research about centrality measurement. First, on a research about graph centrality-based spam SMS detection, centrality measurement is used for SMS detection that contains spam or not using several machine learning methods such as random forest, support vector machine (SVM), and naïve Bayes. The centrality type that used on the research is degree centrality and closeness centrality. The result in the study showed that degree centrality gave the best precision and recall results with $81 \%$ and $76 \%$, respectively [1]. In another research about implementing term weighting for text categorization, centrality is used to categorize a single label text that was implemented using term weighting (TW), which represents the term value of each centrality type. In the research, the graph is implemented as a directed graph. The graph model represents the co-occurrence of terms or words in each document or paragraph. The centrality type that used in the research is degree centrality, indegree, out-degree, and closeness centrality with the best accuracy is $96.61 \%$ on degree centrality [2]. 


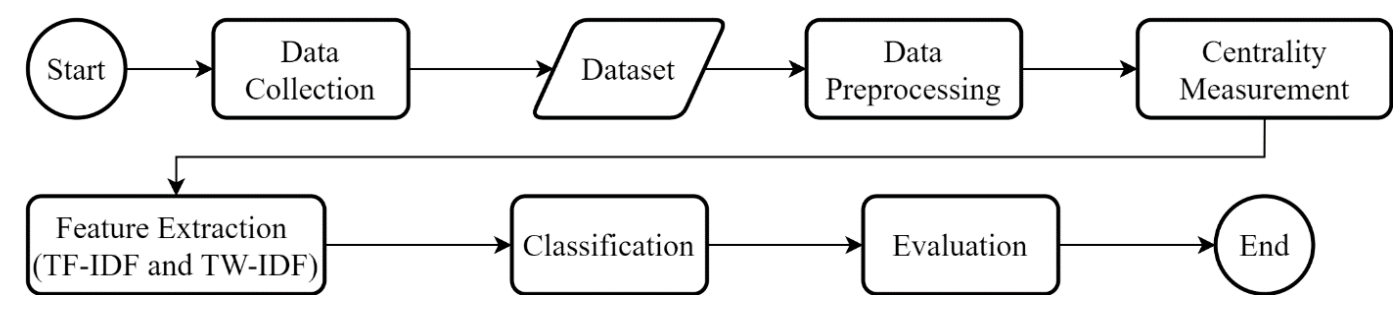

Figure 1. The Classification Process in This Research

In the study about the effectivity of graph-based term The classification methods used in this research are weighting (TW), a comparison about term feature such Naïve Bayes and SVM. Naïve Bayes is a probabilistic as TF-IDF, TW, TW-IDF and TW-SRW (Supervised method based on Bayes theorem with strong Relevance Weighting) is conducted on different independence assumption between each feature and has datasets. The SVM method achieves the best recall score been successfully applied in other studies [8][9][10]. at $98.02 \%$ [3]. Next, study about keyword extraction Meanwhile, Support Vector Machine (SVM) is one of from Arabic documents that used four type centralities the most widely used classification methods and has (degree, betweenness, closeness, and eigenvector been successfully applied in many applications [11]. centrality). In the research also use several machine learning methods for identify keywords including multilayer perception, naïve Bayes, random forest, and oneR. The result shows the performance of all machine learning method above are good results in precision of 95.5\% until $96.4 \%$ [4].

The purpose of this research is to find the central or important word from The Quran. All the centralities type combined with TW-IDF are used for classification. So, we can know the effect of centrality words on the classification system. In addition, this research also compares the performance between each feature Furthermore, the studies about classification on Quranic extraction, TF-IDF and TW-IDF, with two types of verse topics also have been done in recent years. First, GoW models. Also, this research compares two machine the study in 2019 that was built a multilabel learning methods, Naïve Bayes and SVM.

classification system from Quranic verses in English translation using K-Nearest Neighbor (KNN) and 2. Research Method

Weighted TF-IDF. The result shows the best average hamming loss score is 0.1349 with the k-score is 25 [5]. Next, the study in 2019 was using Quranic verse in In this research, centrality measurement on the English translation dataset and compare any feature multilabel classification of The Quran verses topic is selection with any machine learning methods such as carried out with several main processes, those are data naïve Bayes, SVM, and ANN. The result shows that the collection, data preprocessing, centrality measurement, best hamming loss score is 0.0938 when naïve Bayes feature extraction, data classification, and evaluation of method is used, and the type of feature selection is called performance of classification system. The design mutual information [6]. Another research about topic scheme of the system can be look in Figure 1.

classification in Al-Baqarah, one of the chapters of The Quran, with three topics, named iman (faith), ibadah (rituals), and akhlaq (morals). Several classification methods are used in its research such as naïve Bayes, SVM, J48, and KNN classifier. The result shows SVM and $\mathrm{J} 48$ gives a higher accuracy of $85 \%$ [7].

Based on previous related studies, this research builds a Graph of Word (GoW) model which represents words in all documents (all verses) of The Quran. GoW model built into two models. First, the GoW model without stopword removal and second GoW model with stopword removal. In the Graph of Word model, some nodes were connected with edges. Nodes represent a word of verses and edges represent co-occurrence relationship between a word of verses and a relationship between a word from the last verse with the first word in the next verses. Centrality measurements that will be used in this research are degree centrality, betweenness centrality, and closeness centrality.

\subsection{Data Collection}

The dataset used in this study is The Quran data with the original The Quran language (Arabic language). The Quran data was taken from an international project called Tanzil.net which provides the verified text of The Quran in Unicode [12]. In this study, we will used eight topics such as Aqidah (faith), Akhlaq (morals), Syariah (laws), Ilmu (knowledge), Kisah (stories), Alam Dunia (universe), Alam Akhirat (hereafter), dan Alam Ghaib (the unseen). These topics are based on the topics published by the Hadith Study Center [13]. The labeling process is done during the data scraping from the website.

The number of data used to build the Graph of Word (GoW) model are 6236 verses, which represent all of the verses in The Quran. This is because, in constructing the GoW, we want to know which words are the most central in The Quran. However, the number of verses

DOI: https://doi.org/10.29207/resti.v5i3.3171

Creative Commons Attribution 4.0 International License (CC BY 4.0) 
Table 2. Verse Samples from The Quran Dataset

\begin{tabular}{|c|c|c|c|}
\hline Verse & Translation & $\begin{array}{l}\text { Verse } \\
\text { Number }\end{array}$ & Topics \\
\hline بسم الله الرحمن & $\begin{array}{l}\text { In the name of } \\
\text { Allah, most } \\
\text { benevolent, ever- } \\
\text { merciful. }\end{array}$ & $1 \mid 1$ & $\begin{array}{l}\text { Aqidah } \\
\text { (faith) }\end{array}$ \\
\hline العالمين لله رب & $\begin{array}{l}\text { All Praise Be to } \\
\text { Allah, Lord of all } \\
\text { the worlds. }\end{array}$ & $1 \mid 2$ & $\begin{array}{l}\text { Aqidah } \\
\text { (faith), } \\
\text { Syariah } \\
\text { (laws) }\end{array}$ \\
\hline الرحمن الرحيم & $\begin{array}{l}\text { Most beneficent, } \\
\text { ever-merciful. }\end{array}$ & $1 \mid 3$ & $\begin{array}{l}\text { Aqidah } \\
\text { (faith) }\end{array}$ \\
\hline مالك يوم الدين & $\begin{array}{l}\text { King of the Day of } \\
\text { Judgement. }\end{array}$ & $1 \mid 4$ & $\begin{array}{l}\text { Aqidah } \\
\text { (faith) }\end{array}$ \\
\hline إيتاك نعبد و إياك & $\begin{array}{l}\text { You alone we } \\
\text { worship, and to } \\
\text { You alone turn for } \\
\text { help. }\end{array}$ & $1 \mid 5$ & $\begin{array}{l}\text { Aqidah } \\
\text { (faith), } \\
\text { Akhlak } \\
\text { (morals) }\end{array}$ \\
\hline المستقام الصر اط & $\begin{array}{l}\text { Guide us (O Lord) } \\
\text { to the path that is } \\
\text { straight }\end{array}$ & $1 \mid 6$ & $\begin{array}{l}\text { Aqidah } \\
\text { (faith), } \\
\text { Syariah } \\
\text { (laws) }\end{array}$ \\
\hline أنعمت عليهم اطلين & $\begin{array}{l}\text { The path of those } \\
\text { You have blessed, } \\
\text { Not of those who } \\
\text { have earned Your } \\
\text { anger, nor those } \\
\text { who have gone } \\
\text { astray. }\end{array}$ & $1 \mid 7$ & $\begin{array}{l}\text { Aqidah } \\
\text { (faith), } \\
\text { Syariah } \\
\text { (laws) }\end{array}$ \\
\hline
\end{tabular}

Table 3. An Example of Tokenization

\begin{tabular}{|c|c|}
\hline Before Tokenization & After Tokenization \\
\hline قل هو الله أحد & 'قل'، ,'هو , ,'الله','أحد' \\
\hline
\end{tabular}

which are included in the classification process is 4747 verses, since based on our data source, these are the verses that have been labeled with the topics, whereas the remaining verses (1489) have not been labeled. Some verses from the dataset are listed in Table 1.

\subsection{Data Preprocessing}

Before we build the Graph of Word model and the whole classification system, the data will be preprocessed first. In this research, the preprocessing are tokenization and stopword removal. Tokenization is the initial stage of text processing which breaks one sentence into several tokens, which in this case are words. The purpose of tokenization is to create a Bag of Word model that will be used for constructing the Graph of Word models and classification process. An example of the tokenization process is illustrated in Table 2.

Following the tokenization process, the next step is stopword removal. Stopword removal is the process of removing words that oftenly appear and consider meaningless. Because this study is using the Arabic language, therefore the stopwords are also Arabic. The words 'أنتما، ,'هو', 'أنت' that have meant 'you', 'he', 'we'
Table 1. An Example of Stopword Removal

\begin{tabular}{|c|c|}
\hline Before Stopword Removal & After Stopword Removal \\
\hline 'قل' ,'هو' ,'الله' ,'أحد' & 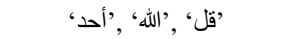 \\
\hline \multicolumn{2}{|c|}{ Translation } \\
\hline $\begin{array}{c}\text { Say: He is Allah, the One } \\
\text { and Only. }\end{array}$ & $\begin{array}{c}\text { Say: Allah, the One and } \\
\text { Only. }\end{array}$ \\
\hline
\end{tabular}

are also removed from the dataset. This removal is performed to study the effect of stopword removal, as well as to improve the performance of the whole classification process. This process is common in text processing. The removal is not intended to change the verse itself, which is totally forbidden in Islam. An example of the stopword removal process is given in Table 3.

\subsection{Centrality Measurement}

Before we measure centrality, we must build a Graph model first. The graph is a collection of vertices that are interconnected with each other. If the vertices or nodes are symbolized by $\mathrm{V}$ and edges are symbolize by $\mathrm{E}$, then the graph can be defined as $G=(V, E)$. In this research we will build a Graph of Word model with the type of graph is an undirected graph. Graph of Word model is represented all of verses in The Quran with nodes represent the word of verse and edges represent cooccurrence relationship between a word of verses and relationship between word from last verse with first word in the next verses. If in one verse or between verses there are the same pair of nodes, it represents edge weight.

The example Graph of word model can be look in Figure 2 that build from Annas chapters with six verses. The edge weight value from this model represents the number of pair words that appear in one verse or between verses. For the example in node 'الناس' (human) and 'ملك' (king) have edge weight value is 2. Because the relationship between node 'الناس' (human) and 'ملاس' (king) appears two times in annas chapter.

Graph of Word model will be built into two models. The first model is without stopword removal process and the second model is with stopword removal process. For scheme of the centrality measurement process can be look in Figure 3.

After we built the GoW model, the next step is centrality measurement process. In graph theory, centrality is an important concept to determine the important nodes in a graph model. In this research we will use three popular types of centrality in network science such as degree centrality, betweenness centrality, and closeness centrality [14]. 


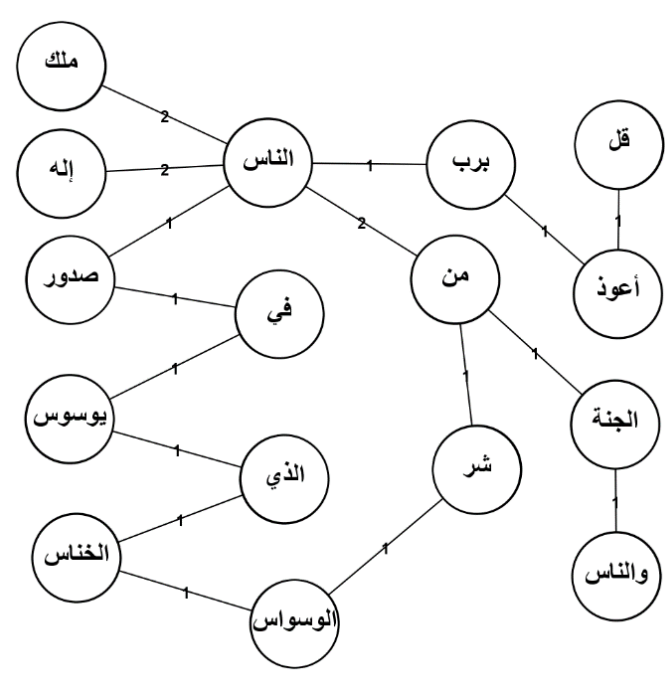

Figure 2. A Portion of The Graph of Word of The Quran

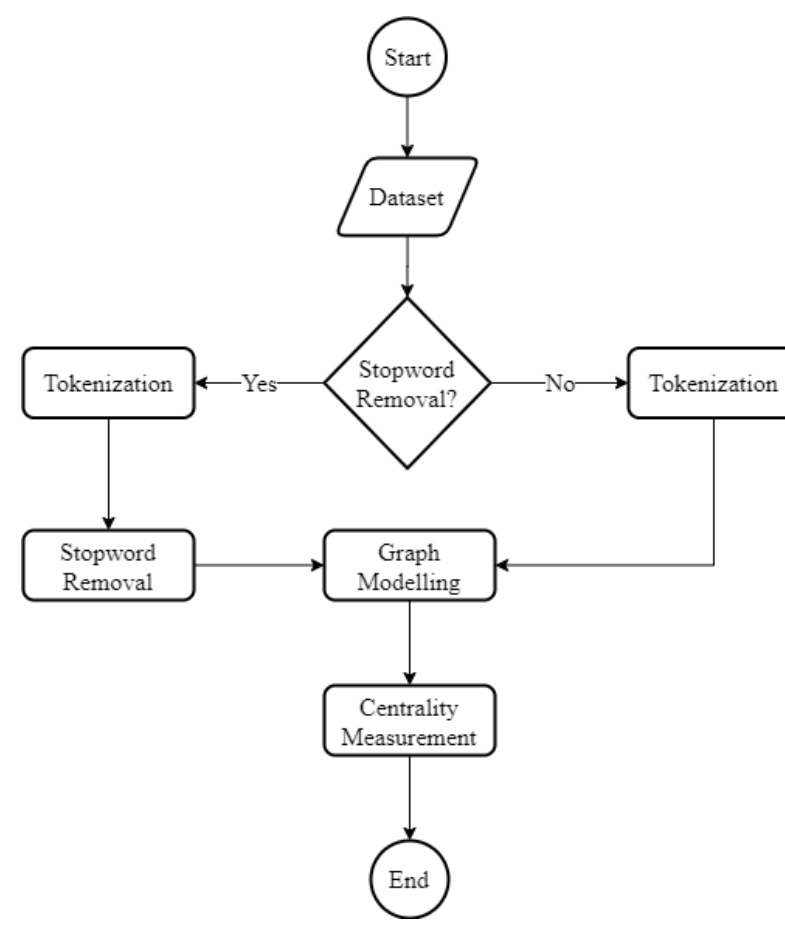

Figure 3. The Centrality Measurement Process

\subsubsection{Degree Centrality}

Degree centrality is calculated based on the degree of the nodes which represent the number of edges connected to the nodes. In GoW, the degree centrality of the node $V_{i}$ represents the number of words that co-occur with words that have a relationship with node $V_{i}[15]$. In our model, the node $V_{i}$ is considered to have a relationship with $i d f_{i}=\log _{10}\left(\frac{N}{d f_{i}}\right)$ another node $V_{j}$, if the word that is represented by $V_{j}$ appears before or after the word represented by $V_{i}$ in a verse. Therefore, the degree centrality can be computed with,

$$
C_{D e g}\left(V_{i}\right)=\frac{\left|N\left(V_{i}\right)\right|}{|V|-1}
$$

where $C_{\text {Deg }}\left(V_{i}\right)$ is the degree centrality value of node $V_{i}$ and $N\left(V_{i}\right)$ is the set of nodes connected to $V_{i}$ and $V$ is the total of nodes number in the graph.

\subsubsection{Betweenness Centrality}

Betweenness centrality is defined as how many times a node acts as a bridge or connector in a graph network [16]. We can compute the betweenness centrality with formula 2 [15],

$C_{\text {Between }}\left(V_{i}\right)=\frac{\sum_{V_{i} \neq V_{j} \neq V_{k} \in V} \frac{\sigma\left(V_{j}, V_{k} \mid V_{i}\right)}{\sigma\left(V_{j}, V_{k}\right)}}{(|V|-1)(|V|-2) / 2}$

where $\sigma\left(V_{j}, V_{k} \mid V_{i}\right)$ is the number of paths that pass node $V_{i}$ and $\sigma\left(V_{j}, V_{k}\right)$ is the number of shortest paths from node $V_{j}$ to node $V_{k}$.

\subsubsection{Closeness Centrality}

Closeness centrality is defined as the number of shortest paths between one node to all the other nodes. We can compute closeness centrality with the following formula [15],

$C_{\text {Close }}\left(V_{i}\right)=\frac{|V|-1}{\Sigma_{V_{j} \in V} \operatorname{distance}\left(V_{i}, V_{j}\right)}$

where $\operatorname{distance}\left(V_{i}, V_{j}\right)$ is the shortest paths between node $V_{i}$ and node $V_{j}$.

\subsection{Feature Extraction}

In text classification, a text needs to be extracted into numeric form because, a computer just processes a numeric number. Therefore, it is necessary to extract text into numeric so that it can be processed by a computer and extract it with the best pattern that may have a huge impact on the classification technique capability [17]. In this research, feature extraction will be giving weight to words in the Bag of Word model. One of the popular feature extraction techniques is TF-IDF which is the combination between term frequency (TF) and inverse document frequency (IDF). TF is the number of terms, i.e. generally words, that appear in a document. IDF is the number of documents that contain the certain terms. We can compute TF-IDF with formula 6 [5].

$t f_{t, d}= \begin{cases}1+\log _{10} \operatorname{count}(t, d) & \text { if count }(t, d)>0 \\ 0 & \text { otherwise }\end{cases}$

$w_{t, d}=t f_{t, d} x i d f_{i}$

where count $(t, d)$ represent the number of terms in one document, $d f_{i}$ represent the number of documents that 
Ferdian Yulianto, Kemas Muslim Lhaksmana, Danang Triantoro Murdiansyah RESTI Journal (System Engineering and Information Technology) Vol. 5 No. 3 (2021) 594 - 601

Table 4. The Top Ten Words According to Degree Centrality on The Graph of Word Model without Stopword Removal

\begin{tabular}{|c|c|c|}
\hline Words & Translate & $\begin{array}{c}\text { Degree } \\
\text { Centrality Score }\end{array}$ \\
\hline 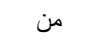 & From & 0.1312 \\
\hline الله اله & Allah & 0.0837 \\
\hline في & At & 0.0665 \\
\hline 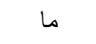 & What & 0.0600 \\
\hline إن إن & That (conjunction) & 0.0545 \\
\hline ولا & Nor (conjunction) & 0.0543 \\
\hline ע & No & 0.0477 \\
\hline أن & That (conjunction) & 0.0473 \\
\hline وما & And what & 0.0445 \\
\hline على & On & 0.0414 \\
\hline
\end{tabular}

Table 5. The Top Ten Words According to Betweenness Centrality on The Graph of Word Model without Stopword Removal

\begin{tabular}{|c|c|c|}
\hline Words & Translate & $\begin{array}{c}\text { Betweenness } \\
\text { Centrality Score }\end{array}$ \\
\hline 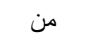 & From & 0.1919 \\
\hline الله & Allah & 0.1092 \\
\hline في & At & 0.0813 \\
\hline ما & What & 0.0606 \\
\hline إن & $\begin{array}{l}\text { That } \\
\text { (conjunction) }\end{array}$ & 0.0556 \\
\hline ورلا & Nor (conjunction) & 0.0541 \\
\hline أن & $\begin{array}{l}\text { That } \\
\text { (conjunction) }\end{array}$ & 0.0444 \\
\hline$y$ & No & 0.0443 \\
\hline على & On & 0.0406 \\
\hline و ما & And what & 0.0360 \\
\hline
\end{tabular}

Table 6. The Top Ten Words According to Closeness Centrality on The Graph of Word Model without Stopword Removal

\begin{tabular}{|c|c|c|}
\hline Words & Translate & $\begin{array}{c}\text { Closeness } \\
\text { Centrality Score }\end{array}$ \\
\hline من & From & 0.4860 \\
\hline الله ل & Allah & 0.4690 \\
\hline 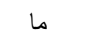 & What & 0.4439 \\
\hline 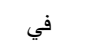 & At & 0.4402 \\
\hline إن إن & That (conjunction) & 0.4370 \\
\hline إلا & except & 0.4284 \\
\hline ע & No & 0.4250 \\
\hline ولا & Nor (conjunction) & 0.4240 \\
\hline لهم & Their & 0.4230 \\
\hline به & With & 0.4207 \\
\hline
\end{tabular}

based on Bayes Theorem, under the strong assumption of independence between each features [9]. Besides that, naïve Bayes have endurance to face the missing value and efficient in computationally [19]. Naïve Bayes can be computed with this following formula,

$$
P(\text { Class }) \prod P\left(\text { Word }_{i} \mid \text { Class }\right) \quad P(\text { Class } \mid \text { Document })=^{(8)}
$$

where $P$ (Class) is the probability of independence class, $P\left(\right.$ Word $_{i} \mid$ Class $)$ is the probability of $W_{\text {ord }}$ in document in class $C$, and $P$ (Class $\mid$ Document $)$ is the probability class of the document.

SVM is one of the supervised learning methods [9]. This method separates data between two or more classes by maximizing the margin between hyperplane with the closest data from each class. We can compute the distance between data with hyperplane using the following formula,

$y_{i}\left(w . x_{i}+b\right) \geq 1 ; i=1,2, \ldots n$

$w_{t, d}$ represent TF-IDF value of word $t$ in document $d$.

After we obtain the centrality value from formula 1,2, and 3 , we can implement that value as weight in term weighting (TW). The process of calculating term weighting is same as TF-IDF where term weighting Before the classification process is carried out using value will be combined with IDF to get TW-IDF [2]. In machine learning methods, we must divide the dataset undirected graph, TW-IDF can be computed by the into training data and test data. In this research, several following formula [18],

$w_{t, d}=t w_{t, d} \times i d f_{i}$

where $t w_{t, d}$ is a value of centrality of term $t$ in document $d$.

\subsection{Classification} test scenarios have been tested with different training data and the result showed the best performance of classification is achieved when the training data is $70 \%$. Therefore, in this research we use the training and testing data at 70:30 composition.

\subsection{Evaluation}

Hamming loss is used to measure the classification naïve Bayes and SVM. Naïve Bayes is one of the performance. Hamming loss is an evaluation method
supervised learning methods that calculate probability that can be used for multilabel classification process that

DOI: https://doi.org/10.29207/resti.v5i3.3171 
Ferdian Yulianto, Kemas Muslim Lhaksmana, Danang Triantoro Murdiansyah RESTI Journal (System Engineering and Information Technology) Vol. 5 No. 3 (2021) 594 - 601

Table 8. The Top Ten Words According to Degree Centrality on The Graph of Word Model with Stopword Removal

\begin{tabular}{|c|c|c|}
\hline Words & Translate & $\begin{array}{c}\text { Degree } \\
\text { Centrality Score }\end{array}$ \\
\hline الله & Allah & 0.1234 \\
\hline 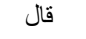 & He Said & 0.0372 \\
\hline قل ل & Say & 0.0267 \\
\hline الأرض & Earth & 0.0263 \\
\hline كان & Take place & 0.0256 \\
\hline قالو ا & They (will) say & 0.0244 \\
\hline آمنوا & Believed & 0.0206 \\
\hline ربك & Your God & 0.0203 \\
\hline عليهم & on Them & 0.0198 \\
\hline كفروا & Disbelieve & 0.0182 \\
\hline
\end{tabular}

Table 9. The Top Ten Words According to Betweenness Centrality on The Graph of Word Model with Stopword Removal

\begin{tabular}{|c|c|c|}
\hline Words & Translate & $\begin{array}{c}\text { Betweenness } \\
\text { Centrality Score }\end{array}$ \\
\hline الله & Allah & 0.3441 \\
\hline قال & He said & 0.0713 \\
\hline كان & Take Place & 0.0486 \\
\hline الأرض & Earth & 0.0447 \\
\hline قل & Say & 0.0412 \\
\hline ق ق الو ا & They (will) say & 0.0399 \\
\hline عليهم & on Them & 0.0316 \\
\hline ربك & Your God & 0.0294 \\
\hline آمنو ا & Believed & 0.0279 \\
\hline ل يوم & Day & 0.0275 \\
\hline
\end{tabular}

Table 7. The Top Ten Words According to Closeness Centrality on The Graph of Word Model with Stopword Removal

\begin{tabular}{|c|c|c|}
\hline Words & Translate & $\begin{array}{c}\text { Closeness } \\
\text { Centrality Score }\end{array}$ \\
\hline الله & Allah & 0.4459 \\
\hline قال & He said & 0.3816 \\
\hline كان & Take Place & 0.3782 \\
\hline 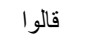 & They (will) say & 0.3747 \\
\hline قل قل & Say & 0.3706 \\
\hline الأرض & Earth & 0.3664 \\
\hline آمنوا & Believed & 0.3647 \\
\hline ربك & Your God & 0.3643 \\
\hline و الله & And to Allah & 0.3632 \\
\hline كفروا & Disbelieved & 0.3630 \\
\hline
\end{tabular}

centrality on classification, naïve Bayes and SVM are implemented with different feature extraction methods such as TF-IDF and TW-IDF with each type of centrality measurement.

\subsection{Quranic Word Centrality}

The effect of centrality is observed in two GoW models: using stopword removal and without stopword removal. Different GoW models demonstrate different word centrality values. After the centrality values of each word are obtained, they are included as feature in the classification process.

Table 4, 5, and 6 listed the top ten result of centrality measurement using GoW model without stopword removal. Most of the top 10 words are stopwords, such as "from", "what", and "at", except that of the word "لله" (Allah). The word "من" (from) has the highest degree, can calculate prediction error (wrong predicted label) betweenness, and closeness centrality values at 0.1312 , and missing error (unpredictable relevant labels) [20]. 0.1919, and 0.4860.

Hamming loss can be computed with the following formula,

Table 7, 8, and 9 listed the top ten result of centrality measurement using GoW model with stopword removal.

$H L=\frac{1}{N} \sum_{i=0}^{N-1} 1\left(L_{i}^{C}[j] \neq L_{i}^{D}[j]\right)$

where $N$ is total label, $L_{i}^{C}[j]$ is result label that generate centrality value at $0.1234,0.3441$, and 0.4459 . All words from classification system, and $L_{i}^{D}[j]$ is label in dataset. in the tables are more meaningful, compared to the that So, the smallest value of hamming loss is shows good in Table 4, 5, and 6, such as "Earth", "Believe", and performance system. Because there are only a few "Disbelieved". This is because the stopwords have been prediction errors or missing errors.

\section{Result and Discussion}

There are two testing scenarios. First, to study the effect of stopword removal in this classification process, we compare the classification with and without the stopword removal process. Second, to compare the classifier, feature extraction methods, and the effect of

\section{filtered out.}

It is also worth to mention that, the word "للاله" (Allah) is always among the top-two words on both scenarios. To be precise, it is the second most central word in the first scenario (Table 4, 5, 6) and the top most central in the second scenario (Table 7, 8, 9). Therefore, the word "لاله" (Allah) is the most central in The Quran according to the centrality measure. The words having the highest

DOI: https://doi.org/10.29207/resti.v5i3.3171

Creative Commons Attribution 4.0 International License (CC BY 4.0) 
Table 10. The Hamming Loss Score of The Topic Classification using Naïve Bayes Method

\begin{tabular}{lcc}
\hline $\begin{array}{c}\text { Feature } \\
\text { Extraction }\end{array}$ & $\begin{array}{c}\text { GoW Model 1 } \\
\text { (without } \\
\text { Stopword } \\
\text { Removal) }\end{array}$ & $\begin{array}{c}\text { GoW Model 2 } \\
\text { (with Stopword } \\
\text { Removal) }\end{array}$ \\
\hline TF-IDF & 0.4385 & 0.4385 \\
\hline TW-IDF Deg & 0.2078 & 0.2078 \\
\hline TW-IDF Bet & 0.2078 & $\mathbf{0 . 2 0 7 7}$ \\
\hline TW-IDF Close & 0.2925 & 0.2789 \\
\hline
\end{tabular}

Table 11. The Hamming Loss Score of The Topic Classification using SVM Method

\begin{tabular}{lcc}
\hline $\begin{array}{c}\text { Feature } \\
\text { Extraction }\end{array}$ & $\begin{array}{c}\text { GoW Model 1 } \\
\text { (without Stopword } \\
\text { Removal) }\end{array}$ & $\begin{array}{c}\text { GoW Model 2 } \\
\text { (with Stopword } \\
\text { Removal) }\end{array}$ \\
\hline TF-IDF & 0.1540 & $\mathbf{0 . 1 5 4 0}$ \\
\hline TW-IDF Deg & 0.1739 & 0.1716 \\
\hline TW-IDF Bet & 0.1770 & 0.1723 \\
\hline $\begin{array}{l}\text { TW-IDF } \\
\text { Close }\end{array}$ & 0.1606 & 0.1605
\end{tabular}

centrality mean they are having the most relation to the other words (degree centrality), connecting the most subgraphs (betweenness centrality), and the closest with the other words in the graph (closeness centrality).

\subsection{Quranic Verse Topic Classification}

Quranic verse topic classification is implemented using two machine learning methods: naïve Bayes and SVM. Since this research is also comparing feature extraction methods, the classification system is implemented with four kinds of feature extraction methods: TF-IDF, TWIDF Deg (degree centrality), TW-IDF Bet (betweenness centrality), and TW-IDF close (closeness centrality). Term weight (TW) value in this research is obtained from the centrality score as illustrated in Table 4, 5, 6, 7, 8 , and 9 . In this study, the classification system also used two types of GoW models which have been described in the previous subsection. Finally, the performance of classification system is measured using hamming loss.

The evaluation result of the topic classification using naïve Bayes is presented in Table 10. The table shows that the lowest (best) hamming loss score is obtained using TW-IDF Bet at 0.2077. This shows that the topic classification using naïve Bayes method achieves the best performance with the feature extraction method TW-IDF Bet. The table also shows that the hamming loss score between the two GoW models is very similar for each feature extraction method. This means that the stopword removal does not significantly affect classification performance.

Table 11 presents the evaluation result of topic classification using SVM. The table shows the lowest hamming loss score is achieved using TF-IDF at 0.1540 .
Similar to Table 10, the use of stopword removal also does not significantly affect classification performance. However, in general, both scenarios show that the GoW model 2 (with stopword removal) has slightly better performance than the other (without stopword removal).

Next, to compare naïve Bayes and SVM, we can compare the hamming loss scores between the two tables. The hamming loss scores in Table 10 (naïve Bayes) are between 0.2077 and 0.4385 , whereas in Table 10 are between 0.1540 and 0.1770 . Therefore, it is clear that SVM outperforms naïve Bayes in Quranic verse topic classification.

\section{Conclusion}

In this research, we investigated how word centrality affects multilabel topic classification on The Quran verses. SVM and naïve Bayes classifiers are implemented with TW-IDF feature extraction to construct classification models and evaluate the effect of word centrality on classification performance. According to the evaluation result, we found that the use of word centrality improves classification performance. The classification model with centrality and stopword removal process shows the best result on both classifiers. When the betweenness centrality is used with naïve Bayes classifier, the best performance is achieved with hamming loss score of 0.21 . While in using SVM, the best hamming loss score is achieved at 0.15 , and thus it is better than the former. Another study also explain that SVM is better than naïve Bayes method when it is implemented without using any additional features [21]. For the future work, different dataset will be considered, such as the translation of The Quran in Indonesia or English. Identifying the most central words in The Quran translation is interesting, because one Arabic word can be translated into multiple words or phrases. For example, the word "ربك" has two words with means "Your God". Some other possible future directions are to employ different classifiers, feature extractions, etc.

\section{References}

[1] A. Ishtiaq, M. A. Islam, M. Azhar Iqbal, M. Aleem, and U. Ahmed, "Graph Centrality Based Spam SMS Detection," Proc. 2019 16th Int. Bhurban Conf. Appl. Sci. Technol. IBCAST 2019, no. March, pp. 629-633, 2019, doi: 10.1109/IBCAST.2019.8667174.

[2] F. D. Malliaros and K. Skianis, "Graph-Based Term Weighting for Text Categorization," Proc. 2015 IEEE/ACM Int. Conf. Adv. Soc. Networks Anal. Min. 2015, pp. 1473-1479, 2015, doi: 10.1145/2808797.2808872.

[3] N. Shanavas, H. Wang, Z. Lin, and G. Hawe, "Supervised graphbased term weighting scheme for effective text classification," Front. Artif. Intell. Appl., vol. 285, pp. 1710-1711, 2016, doi: 10.3233/978-1-61499-672-9-1710.

4] W. Al Etaiwi, A. A. Awajan, and D. Suleiman, "Keywords Extraction from Arabic Documents Using Centrality Measures," 2019 6th Int. Conf. Soc. Networks Anal. Manag. Secur. SNAMS 2019, pp. 237-241, 2019, doi: 10.1109/SNAMS.2019.8931808.

[5] G. I. Ulumudin, A. Adiwijaya, and M. S. Mubarok, "A multilabel classification on topics of qur'anic verses in English translation

DOI: https://doi.org/10.29207/resti.v5i3.3171

Creative Commons Attribution 4.0 International License (CC BY 4.0) 
using K-Nearest Neighbor method with Weighted TF-IDF," $J$. Phys. Conf. Ser., vol. 1192, no. 1, 2019, doi: 10.1088/17426596/1192/1/012026.

[6] F. S. Nurfikri and Adiwijaya, "A comparison of Neural Network and SVM on the multi-label classification of Quran verses topic in English translation," J. Phys. Conf. Ser., vol. 1192, no. 1, 2019, doi: 10.1088/1742-6596/1192/1/012030.

[7] M. I. Rahman, N. A. Samsudin, A. Mustapha, and A. Abdullahi, "Comparative analysis for topic classification in Juz AlBaqarah," Indones. J. Electr. Eng. Comput. Sci., vol. 12, no. 1, pp. 406-411, 2018, doi: 10.11591/ijeecs.v12.i1.pp406-411.

[8] M. Granik and V. Mesyura, "Fake news detection using naive Bayes classifier," 2017 IEEE 1st Ukr. Conf. Electr. Comput. Eng. UKRCON 2017 - Proc., pp. 900-903, 2017, doi: 10.1109/UKRCON.2017.8100379.

[9] A. H. Mohammad, T. Alwada'n, and O. Almomani, “Arabic Text Categorization Using Support vector machine, Naïve Bayes and Neural Network," Glob. Sci. Technol. Forum J. Comput., vol. Volume 5, no. 1, pp. 108-115, 2016, doi: 10.7603/s40601-0160016-9.

[10] N. F. Hardifa and K. M. Lhaksmana, "Topic Classification of Islamic Question and Answer Using Naive Bayes Classifier," vol. 4, no. August, pp. 199-204, 2019, doi: 10.21108/indojc.2019.4.2.346.

[11] A. O. Adeleke, N. A. Samsudin, A. Mustapha, and N. M. Nawi, "Comparative analysis of text classification algorithms for automated labelling of Quranic verses," Int. J. Adv. Sci. Eng. Inf. Technol., vol. 7, no. 4, pp. 1419-1427, 2017, doi: 10.18517/ijaseit.7.4.2198

[12] H. Zarrabi-Zadeh, "Tanzil Documents," 2007. http://tanzil.net/docs/home (accessed Nov. 19, 2020).

[13] A. L. Fathullah, "Indeks Tematik Al-Qur'an," Pusat Kajian Hadist. https://alquranalhadi.com/ (accessed Nov. 27, 2020).

[14] M. Ahmadi, E. Khadangi, S. P. Shariatpanahi, and M. H. Foroughmand-Araabi, "Presenting a computing method for finding the central verse of Quranic surahs," 2018 8th Int. Conf. Comput. Knowl. Eng. ICCKE 2018, no. Iccke, pp. 308-313, 2018, doi: 10.1109/ICCKE.2018.8566366.

[15] F. Boudin and L. U. M. R. Cnrs, "A Comparison of Centrality Measures for Graph-Based Keyphrase Extraction," Ijcnlp, no. October, pp. 834-838, 2013

[16] E. Mailoa, "Analisis Node dengan Centrality dan Follower Rank pada Twitter," J. RESTI (Rekayasa Sist. dan Teknol. Informasi), vol. 4, no. 5, pp. 937-942, 2020, doi: 10.29207/resti.v4i5.2398.

[17] A. I. Kadhim, "Survey on supervised machine learning techniques for automatic text classification," Artif. Intell. Rev., vol. 52, no. 1, pp. 273-292, 2019, doi: 10.1007/s10462-01809677-1.

[18] K. Skianis, F. D. Malliaros, and M. Vazirgiannis, "Fusing document, collection and label graph-based representations with word embeddings for text classification," NAACL HLT 2018 2018 Conf. North Am. Chapter Assoc. Comput. Linguist. Hum. Lang. Technol. - Proc. Student Res. Work., pp. 49-58, 2018, doi: 10.18653/v1/w18-1707.

[19] R. Irmanita, Sri Suryani Prasetiyowati, and Yuliant Sibaroni, "Classification of Malaria Complication Using CART (Classification and Regression Tree) and Naïve Bayes," J. RESTI (Rekayasa Sist. dan Teknol. Informasi), vol. 5, no. 1, pp. 10-16, 2021, doi: 10.29207/resti.v5i1.2770.

[20] R. B. Pereira, A. Plastino, B. Zadrozny, and L. H. C. Merschmann, "Correlation analysis of performance measures for multi-label classification," Inf. Process. Manag., vol. 54, no. 3, pp. 359-369, 2018, doi: 10.1016/j.ipm.2018.01.002.

[21] Sharazita Dyah Anggita and Ikmah, "Algorithm Comparation of Naive Bayes and Support Vector Machine based on Particle Swarm Optimization in Sentiment Analysis of Freight Forwarding Services," J. RESTI (Rekayasa Sist. dan Teknol. Informasi), vol. 4, no. 2, pp. 362-369, 2020, doi: 10.29207/resti.v4i2.1840.

DOI: https://doi.org/10.29207/resti.v5i3.3171 